\title{
Effects of inhaled fluticasone and oral prednisolone on clinical and inflammatory parameters in patients with asthma
}

\author{
R J Meijer, H A M Kerstjens, L R Arends, H F Kauffman, G H Koëter, D S Postma
}

\begin{abstract}
Background-Guidelines state that oral and inhaled corticosteroids are the cornerstone of asthma treatment. The effect of both types of treatment can be assessed by measuring lung and systemic parameters. Treatment for two weeks with either oral prednisolone (30 $\mathrm{mg} / \mathrm{day}$ ), high dose fluticasone propionate $(2000 \mu \mathrm{g} / \mathrm{day}$, FP2000), or lower dose FP $(500 \mu \mathrm{g} / \mathrm{day}$, FP500), both given by a dry powder inhaler, were compared.

Methods-One hundred and twenty patients with asthma were treated for two weeks in a double blind parallel group design. Lung function, asthma symptoms, airway hyperresponsiveness $\left(\mathbf{P C}_{20}\right.$ methacholine and adenosine-5'-monophosphate), sputum eosinophil and eosinophilic cationic protein (ECP) levels were measured as lung parameters. In addition, morning serum blood cortisol, blood eosinophil, and serum ECP levels were measured as systemic parameters.

Results- $\mathbf{P C}_{20}$ methacholine and adenosine-5'-monophosphate showed significantly greater improvement with FP2000 (1.99 and 4.04 doubling concentrations (DC), respectively) than prednisolone (0.90 DC, $p=0.02 ; 2.15$ DC, $p=0.05)$ and marginally more than with FP500 (1.69 and 3.54 DC). Changes in sputum eosinophil and ECP concentrations showed similar trends; the decrease in ECP was significantly greater with FP2000 than with FP500. In contrast, the systemic parameters of steroid activity (cortisol, peripheral blood eosinophils, and serum ECP) decreased to a similar extent with FP2000 and prednisolone but significantly less with FP500.
\end{abstract}

Conclusions-Oral prednisolone $(30 \mathrm{mg} /$ day) was inferior to FP2000 in improving airway hyperresponsiveness to both methacholine and AMP, with similar trends in forced expiratory volume in one second $\left(F E V_{1}\right)$, sputum eosinophil and ECP concentrations. Systemic effects were similar with prednisolone and FP2000 and less with FP500.

(Thorax 1999;54:894-899)

Keywords: asthma; fluticasone; prednisolone; corticosteroids

It is now well established that inflammation of the airway wall plays a central role in the pathophysiology of asthma. Corticosteroids are the cornerstone of anti-inflammatory treatment in asthma. ${ }^{1-4}$ Oral corticosteroids are generally considered to be the standard for airway anti-inflammatory and clinical effects, with only occasional patients having marked systemic effects. ${ }^{5}$ Inhaled corticosteroids produce fewer systemic effects and exert their benefit locally within the airways, although an effect on bone marrow has been suggested. ${ }^{6}$ Studies measuring the effects of oral prednisolone and/or inhaled corticosteroids on clinical parameters in asthma generally show a significant improvement in lung function, airway hyperresponsiveness, rescue medication, and symptoms after treatment periods ranging from one to eight weeks. ${ }^{7-12}$ Few studies have made direct comparisons between oral and inhaled corticosteroids as initial treatment ${ }^{1113}$ or during asthma exacerbations. ${ }^{14}$ The results have generally shown comparable effects on clinical parameters.

It may be more sensitive to measure inflammatory markers in addition to clinical parameters when evaluating the efficacy of corticosteroids in the management of asthma. Induced sputum reflects the degree of local inflammation in the lung and is a promising tool for monitoring eosinophilic inflammation. Several studies have reported a decrease in the numbers of eosinophils and proteins derived from eosinophils-for example, eosinophil cationic protein (ECP)-after corticosteroid therapy. ${ }^{1516}$ So far no study has looked simultaneously at the effects of prednisolone and inhaled corticosteroids on lung and systemic parameters in asthmatic patients. We have followed the dosages advised in the most recently published asthma guidelines at the start of treatment in patients with mild to moderately severe persistent asthma and have compared the effects of $30 \mathrm{mg}$ oral prednisolone, the highest licensed dose of inhaled fluticasone propionate (FP) $(2000 \mu \mathrm{g} /$ day $)$, and a lower dose of FP $(500 \mu \mathrm{g})$ on lung and systemic parameters as initial treatment for a two week period in patients with asthma. ${ }^{17}$

\section{Methods}

PATIENTS

Patients aged $18-56$ years with a diagnosis of asthma were included in the study if they met the following criteria: concentration of methacholine causing a $20 \%$ fall in $\mathrm{FEV}_{1}\left(\mathrm{PC}_{20}\right)$ of $\leqslant 8 \mathrm{mg} / \mathrm{ml}$, at least one positive skin test to 17 most common aeroallergens, reversibility to $\beta_{2}$ agonist $\geqslant 9 \%$ of the predicted $\mathrm{FEV}_{1}$, and ability 
Table 1 Baseline characteristics of the patients

\begin{tabular}{|c|c|c|c|}
\hline & Prednisolone & FP2000 & FP500 \\
\hline No. of patients & 40 & 40 & 40 \\
\hline Median (range) age (years) & $28(18-53)$ & $27(18-48)$ & $27(18-56)$ \\
\hline $\mathrm{M} / \mathrm{F}$ & $14 / 26$ & $14 / 26$ & $13 / 27$ \\
\hline \multicolumn{4}{|l|}{ Smoking (\%) } \\
\hline Current & 28 & 31 & 28 \\
\hline Ex-smoker & 23 & 15 & 23 \\
\hline Non-smoker & 49 & 54 & 49 \\
\hline ICS use at baseline (no/yes) & $13 / 27$ & $13 / 27$ & $10 / 30$ \\
\hline $\mathrm{FEV}_{1}(\%$ pred $)$ & $80(65 ; 91)$ & $79(67 ; 91)$ & $81(70 ; 96)$ \\
\hline Reversibility (\% pred) & $12.0(9.2 ; 17.8)$ & $11.4(9.0 ; 17.2)$ & $12.3(9.2 ; 14.4)$ \\
\hline $\log _{2} \mathrm{PC}_{20}$ methacholine $(\mathrm{mg} / \mathrm{ml})$ & $-0.86(0.36)$ & $-0.83(0.37)$ & $-0.83(0.36)$ \\
\hline $\log _{2} \mathrm{PC}_{20} \mathrm{AMP}(\mathrm{mg} / \mathrm{ml})$ & $1.89(0.56)$ & $3.02(0.54)$ & $2.59(0.67)$ \\
\hline $\operatorname{IgE}(\mathrm{IU} / \mathrm{ml})$ & $251(157 ; 615)$ & $251(85 ; 550)$ & $181(97 ; 631)$ \\
\hline Blood eosinophils (\%) & $5.8(3.6 ; 8.0)$ & $5.0(4.0 ; 6.8)$ & $5.1(2.8 ; 7.9)$ \\
\hline Sputum eosinophils (\%) & $5.5(2.0 ; 14.7)$ & $5.0(1.0 ; 8.0)$ & $5.0(1.67 ; 12.0)$ \\
\hline Serum ECP $(\mu \mathrm{g} / 1)$ & $19.5(10.4 ; 26.8)$ & $13.3(9.9 ; 22.0)$ & $17.1(9.3 ; 24.9)$ \\
\hline Sputum ECP $(\mu \mathrm{g} / \mathrm{l})$ & $78.4(28 ; 292)$ & $73.6(33 ; 250)$ & $95.8(46 ; 233)$ \\
\hline Serum cortisol (nmol/l) & $420(302 ; 563)$ & $425(320 ; 725)$ & $445(265 ; 740)$ \\
\hline
\end{tabular}

Data are expressed as medians with interquartile ranges, unless stated otherwise. $\mathrm{PC}_{20}$ methacholine and $\mathrm{PC}_{20} \mathrm{AMP}$ are expressed as mean (SE).

$\mathrm{FP}=$ fluticasone propionate $\mathrm{ECP}=$ eosinophilic cationic protein ICS $=$ inhaled corticosteroids $\mathrm{FEV}_{1}=$ forced expiratory volume in one second; $\mathrm{PC}_{20}=$ concentration provoking a fall in $\mathrm{FEV}_{1}$ of $<20 \%$.

to expectorate sputum after hypertonic saline inhalation.

STUDY DESIGN

Inhaled corticosteroids were tapered and when possible discontinued completely at least three weeks before the randomisation visit. If patients experienced a worsening of their asthma before complete discontinuation of inhaled corticosteroids for three weeks they were asked to return to the hospital earlier for randomisation in the study. Patients who experienced an exacerbation of their asthma which required a course of treatment with prednisolone were not included. Randomisation was performed by a computerised minimisation method $^{18}$ with stratification according to age, previous dose of inhaled corticosteroids, $\mathrm{FEV}_{1}$ \%predicted, reversibility after $200 \mu \mathrm{g}$ salbutamol, smoking status, serum IgE, and $\mathrm{PC}_{20}$ methacholine. The study was of a double blind, three arm parallel group, double dummy design and lasted for two weeks. Patients received either oral prednisolone (30 mg/day), fluticasone propionate $2000 \mu \mathrm{g}$ (FP2000), or fluticasone propionate $500 \mu \mathrm{g}$ (FP500), both given by Diskhaler dry powder inhalation. Rescue medication consisted of salbutamol $400 \mu \mathrm{g}$ via Diskhaler. No other concomitant pulmonary medication was allowed. Measurements at the start and the end of the two week treatment period were performed on two consecutive days at the same time in the morning. On the first day lung function, reversibility

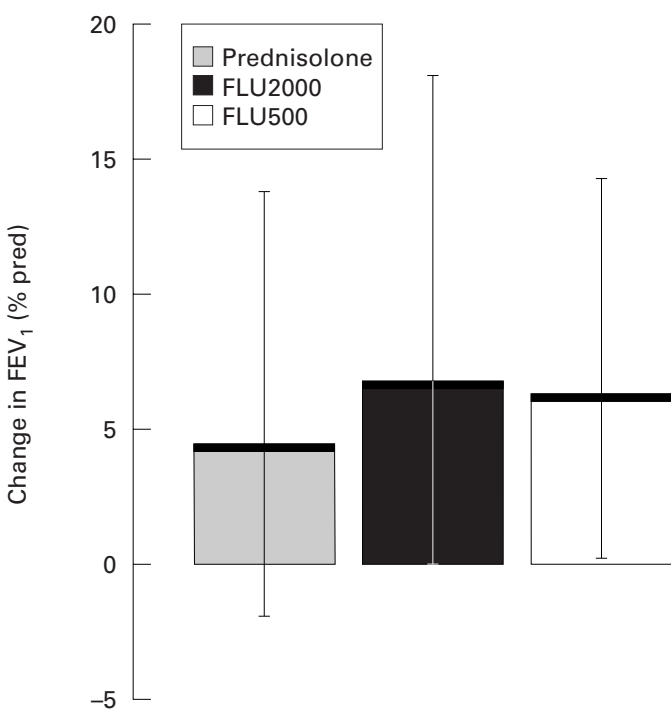

Figure 1 Change in FEV (\% predicted) following treatment with prednisolone, fluticasone propionate

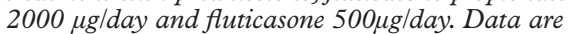
expressed as medians with interquartile ranges. Bold horizontal lines indicate median change.

after salbutamol, blood sampling, and sputum induction were measured and on the second day airway hyperresponsiveness was measured by methacholine challenge. One hour after the final dose of methacholine a second challenge with adenosine-5'-monophosphate (AMP) was performed, an indirect marker of airway inflammation. ${ }^{19} 20$ Peak flow (PEF) (Mini Wright, UK), symptom score (range 0-3), and use of rescue medication were recorded every day in a diary.

The local medical ethics committee approved the study protocol and all participants gave written informed consent.

\section{LUNG FUNCTION}

$\mathrm{FEV}_{1}$ was measured with a calibrated watersealed spirometer according to standardised guidelines. ${ }^{21}$ At least three reproducible values were obtained, the highest value being used for analysis. Methacholine and AMP provocation tests were performed by a two minute tidal

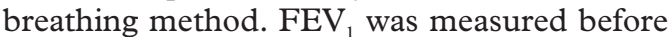
and 20 minutes after $800 \mu \mathrm{g}$ salbutamol given by Diskhaler to test reversibility.

\section{INDUCED SPUTUM}

Fifteen minutes after salbutamol inhalation $(200 \mu \mathrm{g})$ hypertonic saline $(3 \%, 4 \%$, and $5 \%)$ was nebulised (Ultraneb 2000, DeVillbiss,

Table 2 Change in parameters in the three groups following two weeks of treatment

\begin{tabular}{lllll}
\hline & Prednisolone & FP2000 & FP500 & p value \\
& & & & 0.13 \\
FEV $_{1}$ (\% pred) & $4.4(-4.9 ; 10.8)$ & $6.5(0 ; 17.0)$ & $6.3(-1.6 ; 12.4)$ & 0.02 \\
PC $_{20}$ methacholine (DC) & $0.90(0.24$ to 1.56$)$ & $1.99(1.50 \text { to } 2.48)^{\star}$ & $1.69(1.14$ to 2.25$)$ & 0.06 \\
PC $_{20}$ AMP (DC) & $2.15(0.83$ to 3.47$)$ & $4.04(2.85 \text { to } 5.22)^{\star}$ & $3.54(2.53$ to 4.55$)$ & $<0.001$ \\
Blood eosinophils (\%) & $-3.3(-6.9 ;-1.4) \ddagger$ & $-2.1(-5.3 ;-0.4)^{\star \star}$ & $-0.4(-2.1 ; 0.4)$ & 0.03 \\
Sputum eosinophils (\%) & $-3.5(-13.8 ;-0.5)$ & $-4.2(-7.5 ;-1.0)$ & $-2.3(-10.1 ;-0.8)$ & 0.02 \\
Serum ECP $(\mu \mathrm{g} / \mathrm{l})$ & $-8.1(-16.9 ;-1.5) \ddagger$ & $-4.1(-12.4 ; 0.2)$ & $-2.1(-7.3 ; 3.4)$ & 0.06 \\
Sputum ECP $(\mu \mathrm{g} / \mathrm{l})$ & $-38(-148 ;-2.6)$ & $-44(-234 ;-5.3)^{\star \star}$ & $-25(-107 ; 11.2)$ & 0.005 \\
Serum cortisol $(\mathrm{nmol} / \mathrm{l})$ & $-118(-285 ; 51) \ddagger$ & $-155(-285 ;-35)^{\star \star}$ & $0.0(-103 ; 95)$ & \\
\hline
\end{tabular}

$\mathrm{PC}_{20}$ methacholine and AMP are expressed as means with 95\% CI. All other parameters are expressed as medians with interquartile ranges.

$\mathrm{DC}=$ doubling concentrations $\mathrm{ECP}=$ eosinophilic cationic protein.

$\mathrm{p} \leqslant 0.05$ (tested with ANOVA or Kruskal-Wallis).

${ }^{\star}$ FP2000 versus prednisolone; ${ }^{\star \star}$ FP2000 versus FP500; $\neq$ prednisolone versus FP500

$\star \star \star \mathrm{p}$ value in last column is for the difference between all three treatment groups by ANOVA or Kruskal-Wallis test. 


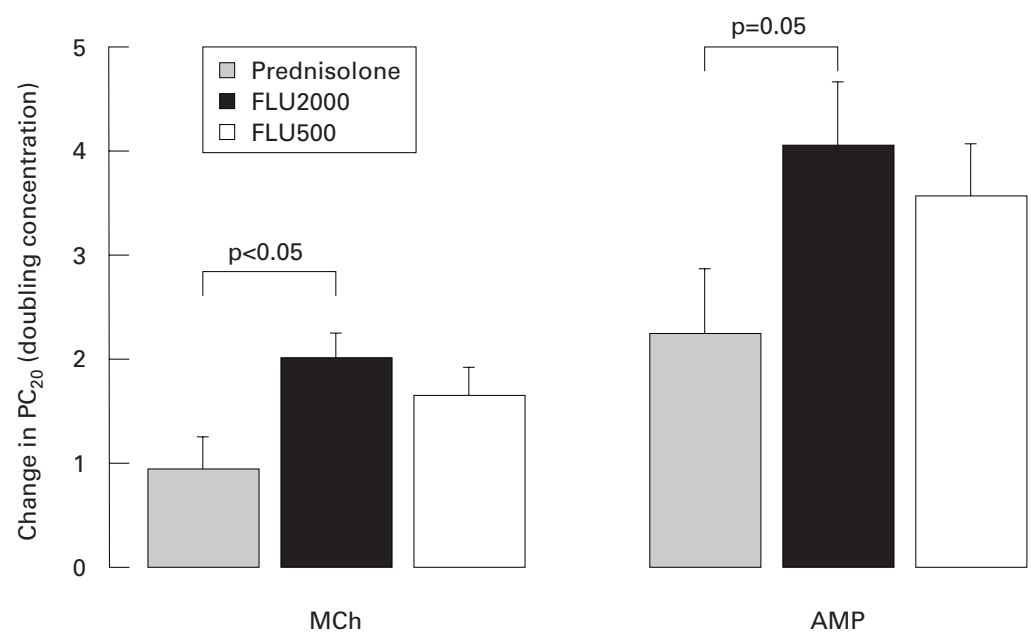

Figure 2 Change in $P_{20}$ doubling concentrations for methacholine (Mch) and $A M P$ following treatment with prednisolone, fluticasone propionate $2000 \mu \mathrm{g} / \mathrm{day}$, and fluticasone $500 \mu \mathrm{g} /$ day. Data are expressed as mean (SE).

Table 3 Diary card data after two weeks of treatment

\begin{tabular}{llll}
\hline & Prednisolone & FP2000 & FP500 \\
\hline PEF (1/min) & $439(405 ; 489)$ & $456(404 ; 495)$ & $434(401 ; 491)$ \\
Daytime symptoms & $0.29(0 ; 1)$ & $0.14(0 ; 0.68)$ & $0.07(0 ; 0.71)$ \\
Rescue medication (no./day) & $0.57(0.11 ; 2)$ & $0.0 \star(0 ; 0.43)$ & $0.0 \ddagger(0 ; 0.93)$
\end{tabular}

Data expressed as medians with interquartile ranges.

Symptoms: maximal score $=3$.

$\mathrm{p} \leqslant 0.05$ (tested with ANOVA or Kruskal-Wallis): ${ }^{\star} \mathrm{FP} 2000$ versus prednisolone; $\ddagger \mathrm{FP} 500$ versus prednisolone

Somerset, Pennsylvania, USA) for each concentration over seven minutes. The output of the nebuliser was calibrated at $1.5 \mathrm{ml} / \mathrm{min}$. Subjects inhaled the hypertonic saline and were encouraged to cough and expectorate sputum into a sputum container. The weight of the induced sputum was measured. An equal volume of dithiothreitol $0.1 \%$ (Sputalysin $10 \%$, Boehring Diagnostics Inc, Sommervillle, New York, USA) was added to the weight of the sputum. The sample was vortexed and placed in a shaking water bath at $37^{\circ} \mathrm{C}$ for 15 minutes and was filtered through a nylon $(48 \mu \mathrm{m})$ gauze. A haematocytometer was used to count the total cell number, viability, and squamous epithelial contamination of the cell suspension. The sputum sample was centrifuged (10 $\left.\mathrm{min}, 450 \mathrm{~g}, 4^{\circ} \mathrm{C}\right)$ and the supernatant was frozen at $-80^{\circ} \mathrm{C}$ for later analysis. The cell pellet was resuspended in phosphate buffered saline (PBS) and cytospins were stained with the May-Grünwald-Giemsa stain. At least 200 non-squamous cells were separately counted by three investigators blinded to the treatment code, mean cell differentials being presented.

BIOCHEMICAL ASSAYS

The concentrations of ECP in serum and sputum supernatant were measured using a fluoroenzyme assay (ImmunoCAP ECP, Pharmacia, Uppsala, Sweden). Blood cell counts were performed by flow cytometry and serum cortisol concentrations were measured using a radioimmunoassay.

\section{STATISTICAL ANALYSIS}

All calculations of $\mathrm{PC}_{20}$ were performed with the base-2 logarithm $\left(\log _{2}\right)$ since this reflects doubling concentrations and normalises the distribution. Patients already responding to saline were assigned a $\mathrm{PC}_{20}$ value half of the lowest concentration applied. Patients not responding to the highest concentration of methacholine or AMP were assigned a value twice the highest concentration applied. According to the study design, patients who showed an increase in symptoms while tapering off their inhaled corticosteroids or who used no inhaled corticosteroids were randomised directly into the study. Incomplete diary cards for these two reasons occurred in 30 of the 118 evaluable patients prior to randomisation. Data from the diary cards were therefore analysed cross-sectionally only at the post-treatment visit and not as change from the randomisation visit. One way analysis of variance followed by Tukey's pairwise multiple comparison tests in the case of significant overall effects were applied for normally distributed variables. For variables not normally distributed the KruskalWallis test was employed, followed by MannWhitney $U$ tests in the case of significant overall effects. Data are expressed as means with SE or medians with interquartile ranges. Skewedness of distributions were assessed with Kolmogorov-Smirnov tests, histograms, and Q-Q plots. Log transformation was applied where useful for normalisation. All analyses were performed with the SPSS version 7.5 package (SPSS-PC, Chicago, USA).

\section{Results}

Between September 1995 and July 1997120 patients were enrolled into the study. Two of the 120 patients were not able to visit the hospital two weeks after start of the treatment (one pregnancy and one loss of study medication). The baseline characteristics of the 120 patients are presented in table 1 ; there were no significant differences between the three treatment groups.

$\mathrm{FEV}_{1}$ increased in all three treatment groups with the trend for a smaller improvement with prednisolone (table 2, fig 1). Mean $\mathrm{PC}_{20}$ methacholine improved with all three treatments, the change with FP2000 (1.99 doubling concentrations (DC)) being significantly larger than with prednisolone $(0.90 \mathrm{DC}, \mathrm{p}=0.02)$. $\mathrm{PC}_{20} \mathrm{AMP}$ also improved in all three groups and the improvement with FP2000 (4.04 DC) was significantly greater than with prednisolone (2.15 DC, $\mathrm{p}=0.05$, fig 2). PEF, symptom score, and use of rescue medication improved in all three treatment groups. Use of rescue medication was significantly lower with FP2000 and FP500 than with prednisolone (table 3).

Eosinophils and ECP in induced sputum decreased significantly in all three groups (table 2). This decrease tended to be least with FP500 (fig 3). Blood levels of eosinophils and ECP did not change significantly with FP500 but prednisolone and FP2000 caused a significant decrease in both parameters. Blood eosinophils $(p \leqslant 0.001)$ and ECP $(p=0.02)$ decreased significantly more with prednisolone than with FP500, and more with FP2000 than with FP500 ( $p=0.003$; table 2, fig 3). Expressing ECP by the number of eosinophils 

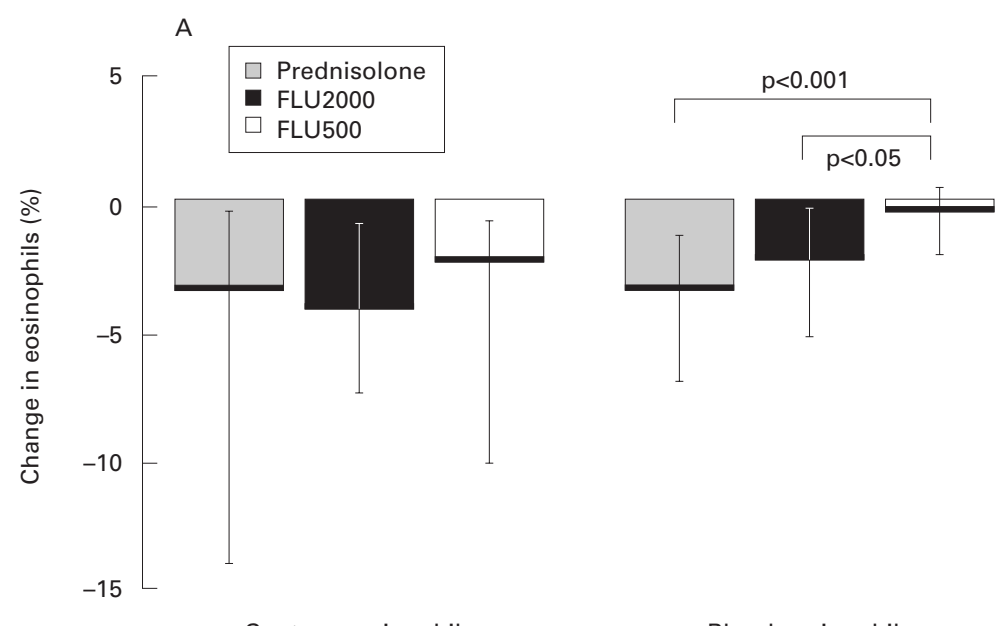

Sputum eosinophils

Blood eosinophils

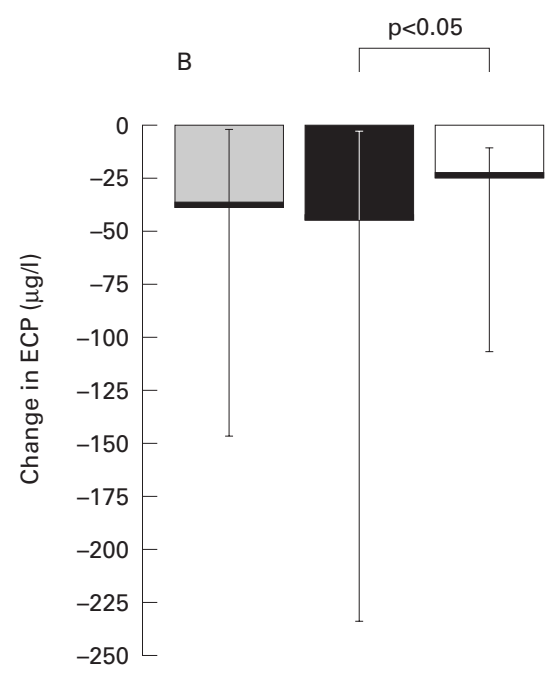

Sputum ECP

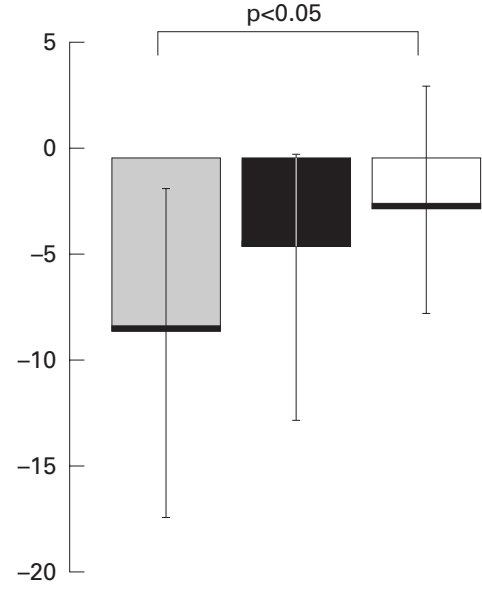

Serum ECP

Figure 3 Change in sputum eosinophil and ECP levels and in blood eosinophils and serum ECP levels with prednisolone, fluticasone propionate $2000 \mu \mathrm{g}$ and fluticasone $500 \mu \mathrm{g}$. Data are expressed as medians with interquartile ranges. Bold horizontal lines indicate median changes.

showed the same differences between the treatment groups as described above. Morning serum cortisol levels were significantly more reduced with both prednisolone $(28 \%$ reduction) and FP2000 (38\% reduction) than with FP500 (0\%) (fig 4). There was no significant difference between prednisolone and FP2000. In five patients in the prednisolone group and four in the FP2000 group the cortisol levels fell below the lower limit of normal values (100 nmol/1).

\section{Discussion}

This study in asthmatic patients showed that two weeks of treatment with high dose inhaled fluticasone $(2000 \mu \mathrm{g})$ is more effective in improving $\mathrm{PC}_{20}$ methacholine and $\mathrm{AMP}$ than either $30 \mathrm{mg}$ oral prednisolone or $500 \mu \mathrm{g}$ fluticasone. In contrast, systemic parameters (blood eosinophils, serum ECP, and serum cortisol) decreased significantly more with oral prednisolone and fluticasone $2000 \mu \mathrm{g}$ than with fluticasone $500 \mu \mathrm{g}$.

Several studies have reported improvements in airway hyperresponsiveness, $\mathrm{FEV}_{1}, \mathrm{PEF}$, symptoms, and use of rescue medication after inhaled or oral corticosteroid treatment. $^{7811} 13152223$ The only available comparison of oral prednisolone and $2000 \mu \mathrm{g}$ fluticasone during asthma exacerbations was made by Levy and coworkers ${ }^{14}$ who reported similar improvements in lung function, symptoms, and treatment success with both treatments. Airway hyperresponsiveness and inflammatory parameters in sputum and blood were not measured. We found a significantly greater reduction in airway hyperresponsiveness following two weeks treatment with fluticasone $2000 \mu \mathrm{g}$ than with $30 \mathrm{mg}$ prednisolone, which was true for both methacholine and AMP. However, the magnitude of change in doubling dilutions was more pronounced for AMP (4.04 and $2.15 \mathrm{DD}$ for fluticasone $2000 \mu \mathrm{g}$ and prednisolone, respectively) than for methacholine (1.99 and 0.90 DD, respectively, table 2 ). This difference between methacholine and AMP has been shown by other authors, suggesting that AMP responsiveness might be more sensitive to changes in airway inflammation than methacholine. ${ }^{20} 24$

In our study morning serum cortisol levels decreased significantly with both prednisolone (28\%) and FP2000 (38\%) but not with FP500. It is known that oral prednisolone has a cross reactivity with cortisol measurements (about $30 \%$ in our laboratory). When we corrected for this cross reactivity the cortisol suppression with prednisolone was $36 \%$ compared with $38 \%$ with FP2000, which does not alter the conclusion of similar suppression with prednisolone and FP2000 using the uncorrected data. In one study larger reductions in morning serum cortisol have been described after a single dose of FP2000 (58\%) or a single dose of $50 \mathrm{mg}$ prednisolone $(87 \%) .{ }^{25}$ Other studies have reported smaller ( $48 \%$ and $-134 \mathrm{nmol} / 1$ from baseline) but significant reductions in serum cortisol concentrations after treatment with $2000 \mu \mathrm{g} /$ day fluticasone for periods of four days and three months, respectively. ${ }^{26}{ }^{27}$ These prednisolone, fluticasone $2000 \mu \mathrm{g}$ and fluticasone $500 \mu \mathrm{g}$. Data are expressed as medians with interquartile ranges. Bold horizontal lines indicate median changes. 
reductions are comparable with our results. It has been suggested in one study that the suppressive effect of inhaled corticosteroids decreases somewhat after one year of treatment. ${ }^{28}$ It is known that fluticasone, when administered orally, is almost $99 \%$ metabolised in the liver ${ }^{29}$ without clinical or systemic effects. This suggests that the inhaled fluticasone that is absorbed from the lungs leads to a reduction in serum cortisol levels.

We expected oral prednisolone and FP2000 to have the same clinical effect with oral prednisolone having a greater systemic effect. However, inhaled FP2000 was significantly more potent clinically than oral prednisolone while their systemic efficacy was equal. This could perhaps be explained by the differences in tissue penetration at the mucosal level, central and peripheral airways deposition, topical steroid potency, and half life. Our results are compatible with fluticasone having a better local effect than oral prednisolone in the epithelium and submucosa. The fact that the receptor affinity and half life of fluticasone are much higher than those of prednisolone and that tissue concentrations of fluticasone are markedly higher than serum concentrations support our hypothesis, ${ }^{30-32}$ but we are unaware of studies that have compared local tissue concentrations of prednisolone and fluticasone in the mucosa and submucosa. Finally, since it has recently been shown that asthmatic inflammation resides not only in the larger airways but also in the peripheral airways, ${ }^{33}$ differences between central and peripheral airway concentrations of prednisolone and fluticasone may also contribute to the more favourable clinical response to fluticasone. The high potency of fluticasone combined with high local concentrations in the peripheral airways, even when lower than in the central airways, ${ }^{30}$ would contribute to the possible difference.

Systemic inflammatory parameters (blood eosinophils and ECP) were not influenced by FP500 while FP2000 and prednisolone caused a significant decrease in both. This might suggest both a direct and indirect effect of FP2000 on blood parameters. The former consists of a reduction in airway inflammation resulting in lower levels of chemokines, cytokines, and a decreased attraction of blood eosinophils into the lung. ${ }^{34}$ Indirect effects of fluticasone-that is, after systemic absorption from the lung tissue-occur in peripheral blood and bone marrow with suppression of both progenitors of eosinophils in blood and of colony forming unit production in the bone marrow, both of which result in reduced numbers of blood eosinophils. ${ }^{65}$ It is also known that inhalation of high doses of corticosteroids reduces the numbers of blood eosinophils by increased apoptosis. $^{36}$

A dose of $2000 \mu \mathrm{g} /$ day fluticasone is relatively high and has been equated to $4000 \mu \mathrm{g}$ of conventional inhaled corticosteroids such as beclomethasone and budesonide. ${ }^{37}$ Further studies should therefore elucidate methods to determine the minimal effective doses of inhaled steroids after two weeks, preferably individualised to each patient. The present study in asthmatic patients shows that treatment with $2000 \mu \mathrm{g}$ fluticasone is superior to oral prednisolone ( $30 \mathrm{mg} /$ day). Two weeks inhalation of FP2000 provides a greater improvement in hyperresponsiveness than oral prednisolone in a dose of $30 \mathrm{mg} /$ day) whereas their systemic effects tended to improve more with FP2000 (fig 3). It is still conceivable that higher doses of oral prednisolone $(40-60 \mathrm{mg}$ / day) would be comparable clinically to FP2000. However, this would also increase the systemic effects of prednisolone. We realise that FP2000 is much more expensive than oral prednisolone; nevertheless, a high dose of inhaled corticosteroids may be favoured over oral prednisolone because of its superior clinical efficacy in our study, and because of rare but severe side effects of oral prednisolone such as steroid induced diabetes. ${ }^{38}$ Our results are compatible with the advice of a $2-4$ fold increase of inhaled corticosteroids in selfmanagement of asthma exacerbations instead of treatment with oral prednisolone $(30 \mathrm{mg}$ / day). Such comparisons during exacerbations need to be further investigated.

Our findings are in contrast to statements in international guidelines ${ }^{13}$ in which oral prednisolone in a dose of $30 \mathrm{mg} /$ day is regarded as "maximum therapy" for asthma control at the start of treatment. We found inhaled fluticasone in a dose of $2000 \mu \mathrm{g} /$ day to be superior to oral prednisolone as initial treatment. A small dose response relation was seen on clinical parameters in favour of fluticasone in a dose of $2000 \mu \mathrm{g} /$ day compared with $500 \mu \mathrm{g} /$ day. However, the systemic effects of higher doses of inhaled fluticasone were also significantly greater.

The authors thank B Aalders, B Dijkhuizen, H Lange, D de Reus, M Swierenga-van der Veen, and J Zonderland for technical assistance. The study was funded by the University of Groningen, Glaxo Wellcome, Pharmacia-Upjohn, the Jan Cornelis de Cock Foundation, and the University Hospital Groningen.

1 Global Initiative for Asthma. Global strategy for asthma management and prevention. NHLBI/WHO Workshop Report 95-3659. Bethesda, Maryland: 1995.

2 Meijer RJ, Kerstjens HAM, Postma DS. Comparison of guidelines and self-management plans in asthma. Eur Respir f 1997;10:1163-72.

3 British Thoracic Society, et al. The British guidelines on asthma management: 1995 review and position statement Thorax 1997;52(Suppl 1):S1-21.

4 Tattersfield AE. Limitations of current treatment. Lancet 1997;350:S1124-7.

5 Smith R. Corticosteroids and osteoporosis. Thorax 1990;45: 573-8.

6 Woolley MJ, Denburg JA, Ellis R, et al. Allergen-induced changes in bone marrow progenitors and airway responsiveness in dogs and the effect of inhaled budesonide on these parameters. Am $\mathcal{F}$ Respir Cell Mol Biol 1994;11:600-6.

7 Lawrence M, Wolfe J, Webb DR, et al. Efficacy of inhaled fluticasone propionate in asthma results from topical and fluticasone propionate in asthma results from topical and not from sys

8 Pearlman DS, Noonan MJ, Tashkin DP, et al. Comparative efficacy and safety of twice daily fluticasone propionate powder versus placebo in the treatment of moderate asthma. Ann Allergy Asthma Immunol 1997;78:356-62.

9 Dahl R, Lundback B, Malo JL, et al. A dose-ranging study of fluticasone propionate in adult patients with moderate asthma. International Study Group. Chest 1993;104:1352-8.

10 Djukanovic R, Homeyard S, Gratziou C, et al. The effect of treatment with oral corticosteroids on asthma symptom and airway inflammation. Am F Respir Crit Care Med 1997; 155:826-32.

11 Jenkins CR, Woolcock AJ. Effect of prednisone and beclomethasone dipropionate on airway responsiveness in asthma: ethasone dipropionate on airway responsivene

12 Juniper EF, Kline PA, Vanzieleghem MA, et al. Long-term effects of budesonide on airway responsiveness and clinical asthma severity in inhaled steroid-dependent asthmatics. Eur Respir f 1990;3:1122-7. 
13 Bosman HG, Uffelen van R, Tamminga JJ, et al. Comparison of inhaled beclomethasone dipropionate 1000 micrograms twice daily and oral prednisone $10 \mathrm{mg}$ once daily in asthmatic patients. Thorax 1994;49:37-40.

14 Levy ML, Stevenson C, Maslen T. Comparison of shor courses of oral prednisolone and fluticasone propionate in the treatment of adults with acute exacerbations of asthma in primary care. Thorax 1996;51:1087-92.

15 Claman DM, Boushey HA, Liu J, et al. Analysis of induced sputum to examine the effects of prednisone on airway inflammation in asthmatic subjects. $\mathcal{F}$ Allergy Clin Immunol 1994;94:861-9.

16 Robinson DS, Assoufi B, Durham SR, et al. Eosinophil cationic protein (ECP) and eosinophil protein X (EPX) concentrations in serum and bronchial lavage fluid in concentrations in serum and bronchial lavage fluid in 1995;25:1118-27.

17 National Heart, Lung and Blood Institute. New NHLBI guidelines for the diagnosis and management of asthma. Lippincott Health Promot Lett 1997;2:1,8-1,9.

18 Pocock SJ. Clinical trials, a practical approach. Chichester: John Wiley and Sons, 1983.

19 Pauwels R, Joos G, van der Straeten M. Bronchial hyperresponsiveness is not bronchial hyperresponsiveness is not bronchial asthma. Clin Allergy 1988;18:317-21.

20 Weersink EJ, Douma RR, Postma DS, et al. Fluticasone propionate, salmeterol xinafoate, and their combination in the treatment of nocturnal asthma. Am $\mathcal{F}$ Respir Crit Care Med 1997;155:1241-6.

21 Sterk PJ, Fabbri LM, Quanjer $\mathrm{PhH}$, et al. Airway responsiveness: standardized challenge testing with phar-
macological, physical, and sensitizing stimuli in adults. Eur macological, physical, and sensitizin

22 Chervinsky P, van AA, Bronsky EA, et al. Fluticasone propionate aerosol for the treatment of adults with mild to moderate asthma. The Fluticasone Propionate Asthma Study Group. 7 Allergy Clin Immunol 1994;94:676-83.

23 Keatings VM, Jatakanon A, Worsdell YM, et al. Effects of inhaled and oral glucocorticoids on inflammatory indices in asthma and COPD. Am $\mathcal{f}$ Respir Crit Care Med 1997; 155:542-8.

24 Oosterhoff Y, Koeter GH, De Monchy JG, et al. Circadian variation in airway responsiveness to methacholine, propranolol, and AMP in atopic asthmatic subjects. Am Rev Respir Dis 1993;147:512-7.

25 Tan KS, Grove A, Cargill RI, et al. Effects of inhaled fluticasone propionate and oral prednisolone on lymphocyte $\beta_{2}$-adrenoceptor
1996;109:343-7.
26 Clark DJ, Lipworth BJ. Adrenal suppression with chronic dosing of fluticasone propionate compared with budesonide in adult asthmatic patients. Thorax 1997;52:55-8

27 Boe J, Bakke PS, Rodolen T, et al. High-dose inhaled steroids in asthmatics: moderate efficacy gain and suppression of the hypothalamic-pituitary-adrenal (HPA) axis. Research Council of the Norwegian Thoracic Society. Eur Respir F 1994; 7:2179-84.

28 Fabbri LM, Burge PS, Croonenborgh L, et al. Comparison of fluticasone propionate with beclomethasone dipropionate in moderate to severe asthma treated for one year. Tho $\operatorname{rax} 1993 ; 48: 817-23$.

29 Fuller R, Johnson M, Bye A. Fluticasone propionate: an update on preclinical and clinical experience. Respir Med 1995;89(Suppl A):3-18.

30 Esmailpour N, Hogger P, Rabe KF, et al. Distribution of inhaled fluticasone propionate between human lung tissue and serum in vivo. Eur Respir 7 1997;10:1496-9.

31 Greos LS, Vichyanond P, Bloedow DC, et al. Methylprednisolone achieves greater concentrations in the lung than prednisolone. A pharmacokinetic analysis. Am Rev Respir Dis 1991;144:586-92.

32 Hogger P, Rohdewald P. Binding kinetics of fluticasone propionate to the human glucocorticoid receptor. Steroids 1994;59:597-602.

33 Kraft M, Djukanovic R, Wilson S, et al. Alveolar tissue inflammation in asthma. Am $\mathcal{f}$ Respir Crit Care Med 1996;154:1505-10

34 Bentley AM, Hamid Q, Robinson DS, et al. Prednisolone treatment in asthma. Reduction in the numbers of eosinophils, T cells, tryptase-only positive mast cells, and modulation of IL-4, IL-5, and interferon-gamma cytokine gene expression within the bronchial mucosa. Am F Respir Crit Care Med 1996;153:551-6.

35 Inman MD, Denburg JA, Ellis $R$ et al. The effect of treatment with budesonide or PGE2 in vitro on allergeninduced increases in canine bone marrow progenitors. Am induced increases in canine bone marrow
$\mathcal{F}$ Respir Cell Mol Biol 1997;17:634-41.

36 Meagher LC, Cousin JM, Seckl JR, et al. Opposing effects of glucocorticoids on the rate of apoptosis in neutrophilic and eosinophilic granulocytes. F Immunol 1996;156:4422-8.

37 Kamada AK, Szefler SJ, Martin RJ, et al. Issues in the use of inhaled glucocorticoids. The Asthma Clinical Research Network. Am 7 Respir Crit Care Med 1996;153:1739-48.

38 McEvoy CE, Niewoehner DE. Adverse effects of corticosteroid therapy for COPD. A critical review. Chest 1997; 111:732-43. 